\title{
Política Externa brasileira no imediato pós-Segunda Guerra: Imposição do Alinhamento
}

Brazilian Foreign Policy in the immediate post-World War II: Imposition of Alignment

\author{
Luiz Alfredo Fernandes Lottermann \\ Universidade de Passo Fundo - Passo Fundo - Rio Grande do Sul - Brasil \\ ORCID https://orcid.org/0000-0001-8422-7963
}

\begin{abstract}
Resumo: O presente trabalho visa discutir a política exterior brasileira no imediato pósSegunda Guerra Mundial sob a ótica do conceito de imposição do alinhamento. O fim do conflito trouxe consigo uma nova configuração das relações internacionais. 0 posicionamento brasileiro durante o período foi alvo de diversas análises que buscavam compreender a maneira como o presidente Eurico Gaspar Dutra conduziu a política externa do país. O momento de disputa por áreas de influência entre Estados Unidos da América e União Soviética poderia lograr vantagens ao Brasil. Entretanto, a postura do governo brasileiro não permitiu que o país alcançasse seus objetivos do ponto de vista da política internacional já que seu alinhamento aos norte-americanos foi automático, diferentemente do que defende a imposição do alinhamento. $O$ conceito sustenta que o atendimento das expectativas do governo dos EUA não era simplesmente sinônimo de subserviência aos interesses estadunidenses, mas uma condição a que o Brasil estava sujeito.
\end{abstract}

Palavras-chave: Imposição do alinhamento. Política Exterior brasileira. Brasil pós-1945.

Abstract: This paper aims to discuss Brazilian foreign policy in the immediate post-World War II under the perspective of the imposition-of-alignment concept. The end of the conflict brought, with it, a new configuration of international relations. The Brazilian positioning during the period was the subject of several analyzes that sought to understand the way President Eurico Gaspar Dutra conducted the foreign policy of the country. The moment of dispute over areas of influence between the United States of America and the Soviet Union could bring advantages for Brazil. However, the Brazilian government's stance did not allow the country to achieve its objectives from the point of view of international politics since its alignment with the Americans was automatic, contrary to what it advocates the imposition of alignment. The concept sustains that meeting the US government expectations was not simply subservience to US interests, but a condition to which Brazil was subject.

Keywords: Imposition of alignment. Brazilian foreign policy. Brazil post-1945. 
Política Externa brasileira no imediato pós-Segunda Guerra: Imposição do Alinhamento

\title{
Introdução
}

O imediato pós-Segunda Guerra Mundial colocou o mundo sob uma nova ordem e estabeleceu uma nova organização das relações internacionais, sendo o mundo ocidental comandado pelos Estados Unidos da América (EUA) e a União das Repúblicas Socialistas Soviéticas (URSS) exercendo influência a leste do globo, conforme explica o historiador inglês Eric J. Hobsbawm:

\begin{abstract}
A peculiaridade da Guerra Fria era a de que, em termos objetivos, não existia perigo iminente de guerra mundial. Mais que isso: apesar da retórica apocalíptica de ambos os lados, mas sobretudo do lado americano, os governos das duas superpotências aceitaram a distribuição global de forças no fim da Segunda Guerra Mundial, que equivalia a um equilíbrio de poder desigual mas não contestado em sua essência. A URSS controlava uma parte do globo, ou sobre ela exercia predominante influência - a zona ocupada pelo Exército Vermelho e/ou outras Forças Armadas comunistas no término da guerra - e não tentava ampliá-la com o uso de força militar. Os EUA exerciam controle e predominância sobre o resto do mundo capitalista, além do hemisfério norte e oceanos, assumindo o que restava da velha hegemonia imperial das antigas potências coloniais. Em troca, não intervinha na zona aceita de hegemonia soviética. (HOBSBAWM. 1995, p.179).
\end{abstract}

Essa divisão marcava o fim da era das potências europeias e inaugurava um novo tempo nas relações de poder no plano internacional: e era das superpotências. "Assim, a sociedade internacional europeia foi substituída por uma nova ordem, caracterizada como sociedade internacional global" (WATSON, 1992, apud GOMES, 2016, p. 19).

Os EUA atingiram uma condição jamais antes vista no mundo. No plano financeiro, impuseram na Conferência de Bretton-Woods, em 1944, a supremacia de sua moeda com a implantação do padrão dólar-ouro, a criação do Fundo Monetário Internacional (FMI) e do Banco Mundial. Com relação ao poderio militar, o país possuía o controle dos mares, sua aviação era a mais poderosa, bem como detinha bases militares em todos os continentes do globo, além do domínio das armas atômicas (VIZENTINI, 2004, p.18). No plano diplomático, os Estados Unidos procuraram, por meio da criação de uma entidade global, exercer sua influência.

\footnotetext{
A hegemonia americana consubstanciou-se também no plano diplomático. Na Conferência de Bumbarton OAKS (1944) e na de São Francisco foi estruturada a Organização das Nações Unidas (ONU), visando a salvaguardar a paz e a segurança internacional. Os soviéticos, temendo que os EUA repetissem o boicote de 1919 à Sociedade das Nações, insistiram para que a nova organização fosse sediada em território norte-americano. A medida foi desnecessária, pois a ONU era um organismo de grande relevância para os objetivos diplomáticos de Washington no pós-guerra, uma vez que representou o instrumento jurídico e ideológico do internacionalismo necessário aos seus interesses. (VIZENTINI, 2006, p.15-16).
}

As condições econômicas e políticas da maioria dos países ocidentais após o fim da Segunda Guerra criaram um ambiente propício para a agitação social e a crescente influência dos ideais vindos do leste europeu. Assim, em 1947 os EUA lançaram a Doutrina Truman, uma política de contenção do comunismo, intervindo política e 
militarmente em diversos países. A doutrina estadunidense de contenção do comunismo (Doutrina Truman) traduziu-se em diversos acordos econômicos e tecnológicos em sua área de influência, além da retórica democrática capitalista (STEPHAN, 2016, p. 2). Tem-se, a partir de então a chamada Guerra Fria entre capitalismo e comunismo, representados por EUA e URSS, respectivamente. Vizentini (2004, p. 19) define que

A Guerra Fria constituiu uma estratégia político-militar norte-americana visando, num plano internacional, conter as forças esquerdistas, nacionalistas e anticoloniais emergentes da Segunda Guerra e, implicitamente, um instrumento que buscava manter o mundo capitalista integrado e submisso ao domínio político-econômico dos EUA, utilizado nesse momento para eliminar barreiras a seu internacionalismo.

No Brasil, a queda de Getúlio Vargas e as eleições realizadas em dezembro de 1945 abriram as portas ao liberalismo. O fim do Estado-novo e a eleição democrática de um novo governo alinhava o país com os ideais do ocidente, negando o autoritarismo, embora Eurico Gaspar Dutra, presidente eleito em 1945, tivesse simpatizado com os regimes nazifascistas dos anos anteriores. O governo Dutra, no plano internacional, alinhou-se automaticamente à Washington.

Nesse sentido, o presente trabalho visa analisar o conceito de "imposição do alinhamento" (GOMES, 2016) que busca explicar a atuação da política externa brasileira no imediato pós-segunda guerra mundial.

\section{Principais interpretações da política exterior brasileira pós-1945}

Entre 1930 e 1989 a política exterior brasileira esteve voltada prioritariamente para o desenvolvimento do país. Dessa forma, em sua ação política internacional, o Brasil se colocava em posição de lograr frutos para seu crescimento econômico. Amado Luiz Cervo situa o período dentro do paradigma do Estado desenvolvimentista, que

\footnotetext{
confere nova funcionalidade ao setor externo, inventando o modelo de inserção internacional: a) realizar interesses de uma sociedade complexa; b) conceber o desenvolvimento como expansão da indústria; c) prover de eficiência a política exterior mediante autonomia decisória, cooperação externa, política de comércio exterior flexível e não doutrinária, subordinação da política de segurança, da guerra e da paz, aos fins econômicos e negociação simultânea com os grandes vizinhos, (CERVO, 2003, p.12).
}

O primeiro governo de Getúlio Vargas, entre 1930 e 1945, é o que dá início às aspirações desenvolvimentistas da política externa brasileira. O advento da Crise de 1929 e da chamada Grande Depressão dos anos seguintes acentuou o declínio da hegemonia inglesa e colocou os Estados Unidos na liderança do cenário econômico mundial e o crescimento expressivo da Alemanha nazista propiciou ao país a possibilidade do pragmatismo nas suas relações exteriores: "tratou de negociar com quem lhe oferecesse mais e melhores condições e de tirar vantagem da rivalidade das grandes potências" (FAUSTO, 2018, p.209). 
A Segunda Guerra proporcionou o grande impulso brasileiro rumo à zona de influência norte-americana. Com o bloqueio comercial imposto pela Inglaterra levou a um forte recuo nas relações comerciais entre Brasil e Alemanha, o que favoreceu os EUA. Para além da questão econômica, "os norte-americanos lançaram também uma ofensiva político-ideológica ao promover, entre outras iniciativas, as Conferências Panamericanas em torno de um objetivo comum: a defesa das Américas [...]" (FAUSTO, 2018 p. 210). Vargas então, com sua política externa voltada ao desenvolvimentismo, procurou obter dos Estados Unidos investimentos econômicos.

O fim da Guerra levou também ao fim do primeiro governo de Vargas. A derrota do Eixo foi a derrota do autoritarismo no ocidente, levando a uma crescente onda liberal pelo mundo que atingiu o Brasil ocasionando a queda do Estado Novo e as eleições de 1945. Eurico Gaspar Dutra foi o presidente eleito pela coligação PSD-UDN. O general que outrora foi simpatizante dos governos autoritários da Alemanha e da Itália, passou a representar a retomada da democracia brasileira. Entretanto, o governo do General ficou caracterizado também pela veemente investida contra a esquerda. Dutra temia a agitação social que provinha do movimento sindical que sofria influência do socialismo soviético (VIZENTINI, 2004, p. 17).

Ao fim da Guerra, no plano internacional,

- Brasil permaneceu alinhado aos Estados Unidos ligado por laços de cooperação. No contexto da guerra fria, subsequente à Segunda Guerra Mundial, e estando as nações agrupadas em dois grandes blocos - Leste e Oeste - que englobam comunistas e capitalistas, liderados pela União Soviética e Estados Unidos, respectivamente, o Brasil manteve-se na órbita de influência de seus ex-aliados, os norte-americanos. (CERVO, 1986, p. 76).

O alinhamento aos interesses dos Estados Unidos foi a dinâmica dada por Dutra durante todo seu governo. A justificativa para tal postura da diplomacia brasileira se dá no sentido de que

Para os planejadores políticos brasileiros, o alinhamento aos Estados Unidos deveria conferir ao país um certo número de vantagens, a mais importante das quais seria a manutenção de uma posição militar única na América Latina e sua correspondente posição política. Uma segunda vantagem seria a participação ativa nas conversações de paz do pós-guerra e no estabelecimento de uma nova ordem internacional. (MOURA, 1990, p. 22)

Tal orientação assemelhava-se com o que fora aplicado por Getúlio Vargas no governo anterior. Conforme Gerson Moura, em suas linhas gerais a Política Exterior de Dutra era uma continuação dos posicionamentos adotados por Vargas, sendo que o político gaúcho tinha certa influência na política internacional brasileira mesmo sem ocupar a cadeira presidencial. Isso fica evidente com a nomeação de João Neves da Fontoura para ocupar o Ministério das Relações Exteriores do governo Dutra (MOURA, 1990, p. 26).

Entretanto, o mesmo autor ainda argumenta sobre as diferenças entre a prática de Dutra e Vargas dizendo que 


\begin{abstract}
Apesar de evidentes semelhanças de abordagem, a implementação da política de alinhamento aos Estados Unidos durante o governo Dutra diferiu largamente da mesma política sob Vargas. Enquanto com Vargas o alinhamento foi tomado como um instrumento da política externa brasileira, com Dutra ele tornou-se na prática e realmente o objetivo da política, tanto em termos bilaterais como em termos multilaterais. (MOURA, 1990, p.23)
\end{abstract}

Em outras palavras, a diplomacia brasileira no governo Vargas procurava obter vantagens para o desenvolvimento econômico do país através de sua estratégia de barganha, utilizando-se da posição estratégica do Brasil como maior país da América Latina. Enquanto que, sob o comando de Dutra, o alinhamento aos EUA configurou-se como automático, sem qualquer resistência aos interesses norte-americanos, e sem ter logrado bônus expressivos no plano econômico. Nesse sentido, Moura (1990) caracterizou este como "alinhamento sem recompensas".

Por seu turno, Paulo Gilberto Fagundes Vizentini apresenta uma visão mais incisiva da política externa praticada por Eurico Gaspar Dutra. Para o autor, o alinhamento brasileiro aos EUA demonstrou uma clara subserviência aos interesses yankees. Esclarece seu posicionamento quando diz que

(...) o governo Dutra viria a vincular-se estreitamente à estratégia da Casa Branca. A atuação de Raul Fernandes no Ministério das Relações Exteriores teve um tom de tal forma conservador e subserviente, seguindo fielmente as ordens e decisões norte-americanas sem questionamentos, deixando de lado interesses brasileiros, que muitas vezes eram contrários à política de Washington. (VIZENTINI, 2004, p.21).

Alguns gestos do governo brasileiro evidenciavam sua submissão aos EUA, e sua necessidade demonstrar que o país era seu fiel escudeiro na América Latina. Dois casos foram emblemáticos: o rompimento das relações diplomáticas com a URSS em 1947 e a forte perseguição ao Partido Comunista e ao movimento operário. "Essa política anticomunista de Dutra não se devia apenas às concepções ideológicas e demandas sociais do Governo. Seu caráter um tanto exagerado vinculava-se à necessidade de evidenciar perante os EUA o engajamento do país contra a subversão esquerdista" (VIZENTINI, 2016, p.200).

Para além dependência no campo político e diplomático, Vizentini ainda salienta que no plano econômico, Dutra seguia o receituário liberal, subordinando-se ao capital internacional. A liberalização da economia ao setor externo caminhava com a perseguição à a redução da inflação no plano interno, que resultou numa grande queda dos investimentos públicos. Também, tal política econômica levava o país à desindustrialização. A criação da comissão Abbink-Bulhões, chefiada por John Abbink e Otávio Gouvêa Bulhões, tinha a tarefa de elaborar um plano para o desenvolvimento econômico do Brasil. Entretanto, o objetivo brasileiro de angariar investimentos norteamericanos não se concretizou, tendo a comissão apenas ficado no campo das análises e os EUA cooperado com o país apenas através de recomendações. (VIZENTINI, 2016, p. 200-201). 
Amado Luiz Cervo diagnosticou o período da política exterior brasileira no imediato pós-Segunda Guerra como um momento de hiato liberal entre 1945 e 1947. Isso por que o caráter desenvolvimentista da diplomacia brasileira passou por um breve momento de alinhamento aos interesses do capital internacional. Nesse sentido, o autor aponta que o caráter 01desenvolvimentista da ação externa brasileira não se perdeu nesse momento, porém ela foi guiada pela crença de que o desenvolvimento do Brasil se daria a partir da extração das vantagens de se estar alinhado com as potências do Ocidente (CERVO, 2008, p.46-47).

Esta perspectiva estava alicerçada naqueles que acreditavam no desenvolvimento associado às forças do capital internacional

\begin{abstract}
Os associacionistas vislumbravam um desenvolvimento impelido de fora pelas forças do capitalismo internacional. As relações especiais com os Estados Unidos, matriz do sistema, seriam valorizadas e postas acima de tudo. De lá, sobretudo, adviriam os fatores essenciais de desenvolvimento, tais como capital, empreendimentos e tecnologia e também influência política e ideológica. Para tanto, as condições internas requeridas seriam um sistema regulatório favorável à penetração desses fatores por um lado, e, por outro, a aliança nas esferas política, geopolítica e de segurança. A esfera das relações econômicas internacionais fundia-se, pois, com a esfera ideológica e política. (CERVO, 2008, p.48).
\end{abstract}

Nessa passagem, fica evidente o caráter ideológico para a condução da política externa brasileira no governo Dutra.

\title{
Imposição do alinhamento
}

O conceito de imposição do alinhamento, elucidado por Daniel Costa Gomes (2016), tenta trazer uma perspectiva diferente daquelas que apresentamos anteriormente para a análise da política internacional brasileira após a Segunda Guerra Mundial. Busca explicar o alinhamento brasileiro aos EUA a partir do preceito de que não havia alternativa plausível para a política externa brasileira.

\footnotetext{
o que se entende por "imposição do alinhamento" é uma situação em que não havia alternativas exequíveis ao alinhamento. Essa situação foi derivada das variáveis (internas e externas) que compuseram o processo decisório relativo à formação da política externa nacional da época. Não decorreu, então, de nenhuma força estrangeira que impôs sua vontade sobre uma nação submetida. Ao contrário, o alinhamento foi resultante de uma decisão soberana perante um quadro de falta de opções alternativas viáveis. $O$ termo "imposição", dessa forma, refere-se justamente a isto: inexistência de alternativas efetivamente concretas. Assim, como não havia opções viáveis, o alinhamento impôs-se, e não foi imposto (por uma potência imperial estrangeira). (GOMES, 2016, p. 16)
}

O autor defende sua perspectiva quando analisa que, com término da Segunda Guerra Mundial, o liberalismo saiu vitorioso e teve seus reflexos no Brasil. A queda de Vargas e a formação de partidos políticos é a maior representação desses reflexos. Desse modo, o autor ainda fala em uma “'imposição do liberalismo' também por via do âmbito interno, uma vez que a própria justificativa para a fundação de uma nova ordem político- 
institucional no Brasil foi a oposição ao autoritarismo - ou a afirmação do liberalismo. " (GOMES, 2016, p. 17).

O advento da Guerra Fria e da divisão do mundo em dois blocos distintos capitalista, liderado pelos EUA; e socialista comandado pela URSS - diminuiu o espaço de manobra diplomática do Brasil. Defendendo seus interesses, os norte-americanos realizam uma série de ações no sentido de conter a influência soviética no mundo, sob o preceito de manutenção dos povos e instituições livres (GOMES, 2016, p.59).

Diante desse quadro, Gomes busca rechaçar os argumentos de Cervo (2008) e de Vizentini (2013) dizendo que a política exterior do governo de Eurico Gaspar Dutra apresentava elementos de autonomia decisória. Para ele, o alinhamento aos Estados Unidos é resultado da conjuntura nacional e internacional. São dois os elementos chave para essa interpretação: a ilusão política e a ilusão econômica (GOMES, 2016, p.79). Na questão política, a ilusão se dava pela crença de que o Brasil teria um lugar especial nas relações dos Estados Unidos com a América Latina pelo fato de o país ter sido o único a contribuir militarmente com os Aliados na Guerra. No ponto econômico, a expectativa de recuperação da economia mundial após Bretton Woods (1944), a crença no aumento do preço do café após o fim do preço-teto, a busca pela estabilidade cambial e o controle da inflação levavam o governo a acreditar que seguindo o receituário econômico liberal o Brasil poderia crescer (GOMES, 2016, p.80-82).

\begin{abstract}
o alinhamento tinha uma racionalidade, amparada em interesses políticos e materiais. A não concretização desses interesses na magnitude esperada resultou em interpretações de que o Brasil padecia de "ilusões". Ressalta-se, no entanto, que, no período, essas "ilusões" eram bastante concretas, plausíveis. Por isso, as aspas apostas ao substantivo ilusões, pois, na época, as expectativas do governo Dutra não eram ilusões, apenas posteriormente se transformaram em ilusões. (GOMES, 2016, p.88).
\end{abstract}

Nesse sentido, o autor conclui que o alinhamento da política externa brasileira aos EUA não foi um passo fora da cadência (CERVO, 2008) muito menos entreguista (VIZENTINI, 2013). Mas sim, a única possibilidade diante do contexto nacional e internacional. Para ele,

a adoção da ideologia liberal - e a "opção" pelo alinhamento - não foi uma liberalidade nem uma atitude subserviente. Ao contrário, representou uma via para o desenvolvimento nacional. Tanto é assim que, quando julgado necessário, o Brasil adotou políticas que contrariaram (vertente negativa da imposição) o liberalismo político-econômico, o alinhamento aos Estados Unidos (GOMES, 2016, p.89).

Assim, fica evidente que o autor busca dar uma visão diferenciada à interpretação das relações exteriores do Brasil no período comandado pelo presidente Eurico Gaspar Dutra.

\title{
Considerações finais
}


A partir do exposto, é notório que a discussão acerca das diferentes interpretações da política exterior brasileira do imediato pós-1945 é necessária e pode gerar grandes debates. O conceito de imposição do alinhamento (GOMES, 2016) traz uma importante contribuição para essa discussão, visto que tenta contrapor as análises já consolidadas por diferentes autores.

O conceito em discussão supõe que a política exterior brasileira era sim dotada de autonomia em suas decisões. A imposição do alinhamento busca evidenciar fraquezas apresentadas por Vizentini e sua definição da política exterior de Dutra. A alcunha de subserviente (VIZENTINI, 2016) dada pelo autor tem base nas ações da diplomacia brasileira à época, notadamente o caso do rompimento das relações diplomáticas com a União Soviética

Na verdade, essa ruptura fazia parte de uma política mais ampla e fora amplamente preparada pelo governo. Nesse contexto, o Partido Comunista foi novamente colocado na ilegalidade no mesmo ano, paralelamente à uma repressão do movimento operário. Essa política anti-comunista do governo Dutra não se devia apenas às concepções ideológicas e demandas sociais do governo. Seu caráter um tanto exagerado vinculava-se à necessidade de evidenciar perante os EUA o engajamento do país na luta contra a subversão esquerdista. (VIZENTINI, 2016, p.200).

Esta visão se reforça com os apontamentos de Amado Luiz Cervo, quando diz que

O Brasil deu apoio às teses norte-americanas que regulamentaram pela ONU e pelos novos órgãos multilaterais (Bird, Gatt, FMI) o sistema do pós-Guerra. Firmou a aliança regional e criou facilidades para a penetração econômica dos norte-americanos em detrimento da autonomia interna. Uma política exterior de concessões sem barganha (CERVO, 1994, p. 34).

Portanto, fica evidente a falta de autonomia da política exterior brasileira do governo de Eurico Gaspar Dutra.

A política econômica entreguista de Dutra liberalizava o país e não obtinha quaisquer frutos. Isso se traduz nos resultados da comissão Abbink-Bulhões, que os Estados Unidos não se comprometeram com qualquer apoio econômico concreto ao Brasil (VIZENTINI, 2006, p. 26), o que não desestabilizou em nenhum momento a relação entre os dois países. Conforme novamente Amado Luiz Cervo, no que diz respeito às escolhas feitas pelo governo no plano econômico

O Brasil de Dutra deixou-se, pois, conduzir pelas forças externas, sem produzir os resultados que a margem de liberdade preservada na fase anterior alcançou. Entre 1945-49, o balanço de pagamentos acusou um déficit de US\$ 122,3 milhões porque ao pagamento de serviços somou-se uma evasão líquida de capitais da ordem de US\$ 181 milhões. O liberalismo brasileiro começava o financiar o crescimento das economias centrais (CERVO, 1994, p. 34). 
Política Externa brasileira no imediato pós-Segunda Guerra: Imposição do Alinhamento

Cabe ainda salientar que a posição subserviente e entreguista brasileira no imediato pós-Segunda Guerra teve menos conquistas que a política externa de Juan Perón na Argentina, que sempre manteve uma postura mais independente. À exemplo:

\begin{abstract}
Esperto, o governo de Perón, a exemplo do procedimento pragmático de Vargas, negociaria a adesão ao Tiar pelo desbloqueamento do dinheiro-ouro argentino nos Estados Unidos (equivalente a 2,5 bilhões de pesos), acenando aos fornece- dores americanos com sua utilização para compra de equipamentos à indústria. (CERVO, 1994, p. 35).
\end{abstract}

Portanto, ao contrário do defendido pela imposição do alinhamento, era possível sim manter uma posição mais autônoma que barganhasse melhores dividendos ao Brasil. Sendo assim, a política exterior do governo Dutra sem dúvidas possuía um caráter de subordinação aos interesses norte-americanos, dependente e fruto de uma concepção ideológica entreguista.

\title{
Referências
}

CERVO, Amado Luiz (Coord.). O desafio internacional: a política exterior do Brasil de 1930 aos nossos dias. Brasília, DF: Ed. Universidade de Brasília, 1994. 354 p.

CERVO, Amado L. Inserção internacional: formação dos conceitos brasileiros. São Paulo: Saraiva, 2008. 297 p.

CERVO, Amado Luiz. Relações internacionais da América Latina: velhos e novos paradigmas. 2. ed. São Paulo: Saraiva, 2007. 238 p.

CERVO, Amado Luiz; BUENO, Clodoaldo. História da política exterior do Brasil. 5. ed. Brasília, DF: Ed. Universidade de Brasília, 2015. 605 p.

FERREIRA, Jorge; DELGADO, Lucilia de Almeida Neves (Coord.). O Brasil republicano: o tempo da experiência democrática. 6. ed. Rio de Janeiro: Civilização brasileira, 2016.

GOMES, Daniel Costa. A imposição do Alinhamento: a política externa dos governos Dutra e Vargas (1946-1954). 2016. 147f. Dissertação (Mestrado em Relações Internacionais) - Universidade de Brasília, Brasília. Disponível em: http://repositorio.unb.br/handle/10482/22712. Acesso em: 20 de fev de 2019.

MOURA, Gerson. 0 alinhamento sem recompensas: a política externa do governo Dutra. Rio de Janeiro: Fundação Getúlio Vargas, 1990.

RECKZIEGEL, Ana Luiza Gobbi Setti. O pacto ABC: as relações Brasil-Argentina na década de 1950. Passo Fundo: EDIUPF, 1996. 181 p.

STEPHAN, C. A Ideologia da Bipolaridade: a Introdução da Doutrina de Segurança Nacional (DSN) e as Implicações para a Democracia no Brasil. In: Seminário Internacional de Ciência Política, 1., 2015. Anais... Porto Alegre: UFRGS. 2016. Disponível em: https://www.ufrgs.br/sicp/anais/defesa/. Acesso em: 10 de Mar de 2019.

VIZENTINI, Paulo G. Da Guerra Fria à crise (1945-1989): as relações internacionais do século 20. Porto Alegre: Editora da UFRGS, 2006. 
Política Externa brasileira no imediato pós-Segunda Guerra: Imposição do Alinhamento

VIZENTINI, Paulo G. Fagundes. Relações Exteriores do Brasil (1945 - 1964): o nacionalismo e a política externa independente. Petrópolis: Vozes. 2004. 279 p.

VIZENTINI, Paulo G. Fagundes. Do nacional-desenvolvimentismo à política externa independente (1945-1964). In.: FERREIRA, Jorge; DELGADO, Lucilia (Org.). 0 tempo da experiência democrática: da democratização de 1945 ao golpe civil-militar de 1964. 0 Brasil republicano, v. 3. Rio de Janeiro: Civilização Brasileira, 2016, p. 195-216.

\section{Sobre o autor:}

Luiz Alfredo Fernandes Lottermann, Mestre em História pelo Programa de Pósgraduação em História da Universidade de Passo Fundo e Coordenador de Ensino no Instituto Federal de Educação, Ciência e Tecnologia do Rio Grande do Sul. Email: luiz_lottermann@hotmail.com 